\title{
Participatory Spaces of Mental Health Service User Organizations in the Post-deinstitutional Era: Mapping Roles and Challenges
}

\author{
Hilda Näslund ${ }^{1} \cdot$ Urban Markström $^{1} \cdot$ Stefan Sjöström $^{1}$
}

Published online: 28 August 2017

(C) The Author(s) 2018

\begin{abstract}
By applying the concept of participatory spaces, this article maps and analyzes current research on mental health service user organizations (MHSUOs). We have analyzed research literature from 2006 to 2016 to examine how the role of and challenges facing MHSUOs are formulated in the post-deinstitutional era. The current situation is marked by MHSUOs parallel presence in invited, claimed and popular spaces for participation. The postdeinstitutional era is characterized by a shift in focus from gaining access to such participatory spaces, to critically examining the political opportunities available in these. We further argue that the dominance of psychiatry-specific spaces could prevent MHSUOs from fully exploring their potential for participation in broader social issues.
\end{abstract}

Keywords Mental health - Service user organization · Post-deinstitutional $\cdot$ Participatory spaces

\section{Introduction}

This paper is concerned with research on service user organizations in the mental health area. A wide variety of organizations operate within this field, from small informal grassroots organizations focused on peer support and larger service user-run organizations with paid staff, to nationallevel umbrella organizations (Baumann 2014; Brown et al.

Update 11 April 2018 The PDF version of this article was reformatted to a larger trim size.

Hilda Näslund

hilda.m.naslund@umu.se

1 Department of Social Work, Umeå University, Umeå, Sweden
$2008 \mathrm{~b})$. The role of and challenges facing mental health service user organizations (MHSUOs) as understood in research literature are analyzed in this paper. Specifically, current research is mapped and analyzed from the perspective of how these organizations move through different 'participatory spaces' (Cornwall 2004).

The concept of participatory spaces, introduced by Cornwall (2004), is especially relevant to the analysis of research literature on MHSUOs since issues concerning participation have been central to MHSUOs from the outset. Service users and their organizations have struggled for social and political participation by challenging discriminatory and exclusionary practices of psychiatry and wider society (Beresford and Branfield 2006; Janzen et al. 2007). The growth of MHSUOs gained pace during the 1960s, when patient organizations focusing on advocacy and civil rights emerged throughout the Western world (Crossley 2006; Tomes 2006). These organizations were active in the deinstitutionalization movement, focused on shifting the location of mental health services from enclosed institutions to support integrated in the community (Parr 2008; Rosenberg 2009; Truc Huynh 2014).

MHSUOs have also struggled for service user participation by advocating for the integration of service user knowledge and perspectives in mental health service systems (Ostrow and Adams 2012). These efforts not only relate to MHSUOs gaining access to spaces of policy making, but also to service users challenging the hegemonic discourses of these spaces by articulating alternative perspectives. MHSUO demands for service user participation have to some extent been heeded in the current postdeinstitutional era, with spaces for services user involvement integrated in service systems (Beresford and Branfield 2006; Eriksson 2015; Markström and Lindqvist 2015; Rose, Fleischmann, Tonkiss, Campbell, and Wykes 2003). 
The present situation is further marked by a diversification of MHSUOs, with a visible growth in family organizations and condition-specific groups. This diversification is also reflected in the positions of MHSUOs, where many organizations have shifted their focus toward a more collaborative approach to mental health services (Crossley 2006; Karlsson and Markström 2012; Tomes 2006).

Furthermore, neoliberal restructurings of the mental health area have contributed to new understandings of service user participation. Health and support systems have been influenced by market systems such as New Public Management, with a shift toward plural service providers. These changes are related to the development of hybrid MHSUOs, which are engaged in advocacy activities combined with service provision (Karlsson and Markström 2012; Markström and Karlsson 2013). As a result of this, service users and their organizations are invited to participate both as consumers and providers of mental health services. These dual roles contribute to changed positions within the psychiatric landscape.

The above-described transformations of mental health geographies in the post-deinstitutional era, both with regard to the position of MHSUOs and developments of mental health service systems, motivate us to map and analyze current formulations of MHSUO participation. Guided by the concept of participatory spaces, the aim of this study is to analyze the role of and challenges facing MHSUOs in the post-deinstitutional era, as they are depicted in research. The analysis is conducted on research literature published between 2006 and 2016.

\section{Theoretical Framework}

In the following section, we consider how service user participation constitutes a central concern in the post-deinstitutional era. We then describe the concept of participatory spaces (Cornwall 2004) that will guide our analysis of how the current role of and challenges facing MHSUOs are understood in research.

\section{Social and Political Participation in the Post- deinstitutional Era}

Developments of the mental health field have a strong geographical dimension. Discourses of psychiatry have structured spaces such as the mental hospital, where both social and spatial distance has marginalized people with psychiatric disabilities. The first phase of deinstitutionalization challenged these exclusionary arrangements and focused on transferring mental health services and supports from the 'total institution' of the mental hospital to services such as day centers and sheltered housing which were integrated in the community. In the second phase, the current post-deinstitutional era, these services have been criticized for still constituting institution-like care settings (Markström 2005; Markström and Lindqvist 2015; Rosenberg 2009). Even though the walls of psychiatric hospitals have been dismantled and care provision is now located elsewhere, patients have still been 'walled-in' and grouped together in community clinics and programmes (Rosenberg 2009). Rosenberg (2009) argues that this geography has changed in the post-deinstitutional era. Instead of the psychiatric hospital, it is now community inclusion that constitutes the central point of reference. The focus has shifted from sheltered supports to exploring alternative mental health locations in the open community (Rosenberg 2009).

The post-deinstitutional era is further characterized by increased integration of service user participation in mental health service systems (Burns 2014; Markström and Lindqvist 2015; Rosenberg 2009). Cornwall and Gaventa (2000) argue that new arenas and more direct ways for citizens to influence government are currently being explored and have broadened the definition of service user participation. The concept of participation is in this paper extended beyond processes initiated by authorities, to include autonomous arenas created for service user group engagements. The frame of 'citizen participation' proposed by Gaventa and Valderrama (1999) is applied, bridging definitions of social and political participation (Cornwall 2002). The current involvement of MHSUOs in social activities, policy processes and provisioning has interlinked social and political participation, where both participatory forms potentially contribute to strengthening the social citizenship of service users.

\section{Spaces for Participation}

We will apply the concept of participatory spaces to analyze views in research literature on the role of and challenges facing MHSUOs in the current post-deinstitutional era, in which issues of participation are at the forefront (Cornwall 2004; Rosenberg 2009). Through analyzing how participatory practices are enacted in different kinds of spaces, this theoretical perspective furthers our understanding of the dynamic between institutionalized spaces for participation constituted by authorities and more organic participatory spaces, autonomously created and shaped by service users (Cornwall 2002). Developing the conceptualization of Cornwall (2004) and Gaventa (2004) we analyze the participatory spaces in which MHSUOs operate as 'invited,' 'claimed' or 'popular.' These different participatory spaces are made available for MHSUOs, alternatively occupied or created by them, to achieve social and political change (Cornwall 2004). Participation in a given space relates not only to service users being 
represented or having 'a seat at the table,' but also to the possibility of affecting the discourse by articulating different perspectives, modes of knowledge and authority (Cornwall 2004). The examination of participatory spaces can furthermore decouple the analysis from the institutional arrangements of organizations, to provide a more flexible and situational analysis of the processes in which MHSUOs are involved.

With the stated strategy to strengthen democracy, invited spaces are created to reduce the gap between the state and its citizens. In such spaces, authorities invite MHSUO representatives in the capacity of consultants, to sit in on committees and contribute to policy development. Invited spaces offer MHSUOs connections to traditional mental health service systems. However, these spaces have been criticized for having no effect on established power relations and for rearticulating hegemonic perspectives (de Freitas and Martin 2015). Regardless of the core ambition, invited spaces are created, arranged and controlled by authorities (Cornwall 2004, 2008). Furthermore, these spaces are characterized by vast differences in status as well as heterogeneity with regard to the perspectives of the actors involved (Cornwall 2004).

Claimed spaces represent arenas which previously had no service user representation but have now been occupied by service user groups. Participation is not only enacted through claiming the right to be represented in spaces for policy making, but MHSUOs occupying spaces for service provisioning also have potential to create platforms for the articulation of rights (Cornwall and Gaventa 2000). Just like invited spaces, we define claimed spaces as relational to authorities but these spaces are chosen by service user groups themselves and created through the struggle of social movement organizations to participate (Cornwall 2004; Gaventa 2004). Different actors can have contrasting definitions of participatory spaces. Intermediate spaces between government and civil society can, for instance, be defined by the government as invited spaces, but can for MHSUOs represent claimed spaces (Cornwall and Shankland 2013).

As with claimed spaces, popular spaces originate in grassroots activity but represent spaces created independently of authorities for the purposes of activism, self-help initiatives or social activities. These more autonomous arenas unite service users around a commonality of identifications or perspectives, creating vital spaces for participation (Cornwall 2002, 2004, 2008; de Freitas and Martin 2015; Gaventa 2004). In the absence of authorities, popular spaces can constitute sites for service users to develop their confidence and skills through solidarity and support (Cornwall 2008). They can also make space for constructing alternative narratives of experience and negotiating new forms of knowledge (Cornwall 2004; de Freitas and Martin 2015).
Social and political participation can thus be enacted in the different forms of participatory spaces (Cornwall 2002). Being relational to authorities, invited and claimed spaces have a focus on institutional politics but involvement in these spaces also supports the social participation of service user groups. Popular spaces are rather focused on social participation but also create space for political participation, by constituting sites for political activism and for service user groups to formulate and unite around political demands (Cornwall and Schattan Coelho 2007).

\section{Methods}

Informed by the concept of participatory spaces, this study employs narrative review methodology in order to analyze research literature from the past decade focused on MHSUOs. The method is a suitable approach for our ambition to interconnect and reconceptualize studies on related subjects that use different methodologies (Baumeister and Leary 1997; Werkmeister Rozas and Klein 2010). Rather than a focus on testing hypothesis, the narrative review can apply prior conceptualizations to offer new understandings of research literature (Baumeister and Leary 1997). Our ambition is thereby to illustrate wider patterns in formulations of the role of and challenges facing MHSUOs, than what can be shown by single empirical reports (Baumeister and Leary 1997).

\section{Literature Search Strategies}

To retrieve relevant literature, we conducted electronic bibliographic searches in $\mathrm{EBSCO}^{1}$ and Scopus. A broader search string $^{2}$ was initially used, but the unmanageable number of matches (EBSCO: $n=61,276$, Scopus: $n=2655$ ) led us to further refine our search, guided by our

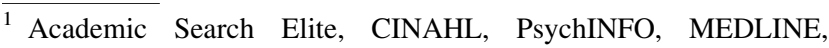
SocINDEX.

2 (psychiatr* OR mental*) AND (communit* OR association* OR movement* OR organization* OR organisation* OR alliance*) AND (consumer* OR survivor* OR ex-patient* OR recover* OR service user* OR service-user* OR patient* OR advocacy OR activis* OR peer-led OR 'peer led' OR peer-support OR 'peer support' OR selfhelp OR 'self help').

3 (psychiatr* OR mental*) AND (communit* OR association* OR movement* OR organization* OR organisation* OR alliance*) AND (civi* OR volunt* OR non-governmental OR NGO OR non-profit OR nonprofit OR 'third sector') AND (consumer* OR survivor* OR expatient* OR recover* OR service user* OR service-user* OR patient* OR advocacy OR activis* OR peer-led OR 'peer led' OR peersupport OR 'peer support' OR self-help OR 'self help').
} 
interest in third sector organizations. The main searches were performed on May 15, 2016, using search terms ${ }^{3}$ selected in consultation with an information specialist and also informed by the search terms used in a previous review on a related subject (Karlsson and Markström 2012). Prior knowledge of important publications in book format led us to include both peer-reviewed articles and book chapters. The database searches were set to include matches in English from 2006 to 2017.

The main search yielded 2133 matches in total (Scopus: $n=726$, EBSCO: $n=1407)$. Initially, the authors discussed a selection of texts to decide on the inclusion criteria as well as defining the characteristics of the organizations to include. We have included a wide spectrum of organizations, from those that are small and focused on peer support to those that are policy-oriented and operating at national level. With regard to the target group of organizations, we have applied a broad definition of mental health, but excluded organizations where people with dementia, addiction problems and intellectual disabilities constitute the main target groups. After deciding on these common principles for inclusion, we screened the abstracts to ascertain whether they were relevant. Our selection was based on the inclusion criteria: (1) a focus on service user organization(s) and (2) falling within the field of mental health. The first author was mainly responsible for the selection, but borderline matches were continuously discussed in the research group. A large number of the matches did not meet the inclusion criteria but focused on topics such as survivors of disasters/cancer, aspects of voluntary community care, NPOs that were not MHSUOs or peer support/service user participation in the public sector without reference to MHSUOs. The vast majority of the matches failed to meet the first criteria. Matches with less than five references were also excluded, leaving 52 texts from the initial search after the selection.

As an additional strategy, we scanned the references of the identified texts and performed hand searches to capture additional literature. A higher frequency of book chapters $(n=13)$ was included for this second step, where 64 texts in English or Swedish were added. These texts were compared to the initial broader search, which identified a large number of these texts $(n=49)$. A total of 116 texts were included; see Table 1 . The fact that the main database search yielded fewer than half of the included texts could be seen as a weakness in the calibration of the search terms. However, these texts have been checked for central search terms excluded from our search string, and no such recurring terms were identified. The virtue of multiple search strategies that are most likely to transcend searches based solely on keywords is that they provide a more comprehensive overview of the research field.
Table 1 Final selection of texts, according to continent/country of analytical focus and methodology

\begin{tabular}{lll}
\hline & Methodology & Continent/country \\
\hline & International: 5 & Qualitative: 29 \\
& Cross-continent: 2 & Quantitative: 24 \\
& North America: 58 & Mixed method: 22 \\
& US: 44 & Theoretical: 30 \\
& Canada: 12 & Descriptive: 8 \\
& Europe: 38 & Literature review: \\
& UK: 24 & 3 \\
& Africa: 4 & \\
& Australia: 8 & \\
Article & Asia: 1 & \\
Book & 102 & \\
chapter & 13 & \\
Dissertation & 1 & \\
Total & 116 & \\
number & & \\
\hline
\end{tabular}

\section{Categorization and the Synthesizing Process}

Included texts $(n=116)$ were read through and categorized according to country of analytical focus and methodological orientation; see Table 1 for an overview. The selection showed a relatively even distribution over the ten-year period, indicating that research has not intensified to address the emerging questions concerning the role of MHSUOs in the post-deinstitutional era. As for the country of analytical focus, i.e., the geographical context of the MHSUOs described/analyzed, North America $(n=58)$ and Europe $(n=38)$ are dominant in the selection. In Table 1, we have singled out research which has a USA $(n=44)$ and UK $(n=24)$ context to highlight the high frequency of such texts. The dominance of research produced in Anglophone countries is visible in many research fields, and the pattern of US dominance within this field of research has been described in a previous study (Karlsson and Markström 2012). The high frequency of texts produced in the UK possibly mirrors the national endorsement of service user research (Patterson et al. 2014; Rose 2015).

A large number of the included texts are focused on MHSUOs in the Global North, and the analysis is therefore bound to reflect issues of participation most relevant to these contexts. Our focus on mapping research literature from a particular theoretical perspective means that this study lacks information on the shifting, specific and local 
conditions of MHSUOs. The susceptibility of organizations to current developments varies, and national and local contexts are highly relevant to the circumstances of specific MHSUOs. Such variations are, however, largely beyond the scope of this article. Our lens of research literature furthermore entails a focus on the role of and challenges facing MHSUOs that are attended to in research. This study should thus be understood as an analysis of central issues of MHSUO participation discussed in research literature rather than an empirical description of the field of MHSUOs.

Included texts originate in many different disciplines, reflecting a lack of disciplinary dominance over this field of research. However, a number of authors are represented in several texts, which is especially noteworthy with regard to Nelson who is the co-author of six texts (Janzen et al. 2007; Nelson et al. 2006a, b, 2007, 2008; Nelson and Lomotey 2006) and Brown who is represented as author or co-author of eight texts (Brown 2009a, b; Brown et al. 2007a, b, 2008a, b, 2010; Brown and Townley 2015). The frequent representation of US authors from community psychiatry studies potentially creates bias to issues central within that context and field. Research focused on MHSUOs is a relatively limited field of research, making it particularly important to be aware of risks for weighted inclusion of literature.

A number of texts were the result of collaborations between service users and researchers (Gillard et al. 2016; Gupta and Roberts 2014). The diversity of research focused on MHSUOs is also reflected in methodological orientation, with a relatively even distribution of qualitative $(n=29)$, quantitative $(n=24)$, mixed method $(n=22)$ and theoretical $(n=30)$ approaches. Texts categorized as descriptive $(n=8)$ focused on describing specific organizations (Barrett et al. 2014; Holland 2010; Swarbrick 2007) or cooperation between organizations (Abdulmalik et al. 2014; Dziadkowiec et al. 2010; Rogers 2010). These texts provided empirical information without specific information about methodology.

The included texts were read through and clustered according to main focus. This grouping of texts provided an overview of included literature and enabled further analysis to be grounded in data by being used as a strategy to elicit a well-adapted theoretical framework (Best et al. 2014). The texts were then re-read with a focus on mapping the role of and challenges facing MHSUOs informed by the perspective of the organizations' presence in invited, claimed and popular spaces for participation. The presentation of our analysis is structured by the activities, organizational form, enactment of service user knowledge and relationships of MHSUOs, dimensions that are central to how MHSUOs involvement in participatory processes are understood in research.

\section{Analysis}

Developments in the field of mental health and in MHSUOs have meant these organizations are present in new arenas and engaging in novel activities. The challenges and value conflicts arising from developments in the role of MHSUOs are frequently described in the included texts (Boyce et al. 2010; Gillard et al. 2016; Nelson et al. 2008; Ostrow and Adams 2012). We argue that these challenges are related to how MHSUOs in the post-deinstitutional era simultaneously participate in social processes related to popular, claimed or invited spaces.

\section{Hybridization of Activities}

By claiming spaces for service provision, MHSUOs now offer alternatives to traditional mental health system services. This development is especially evident in the USA, where peer-provided services by far outnumber traditional services (Goldstrom et al. 2006). The service-providing role of MHSUOs is the main focus of many of the included texts, especially within texts focused on the North American context (Brown et al. 2008a, 2010; Fleury et al. 2012; Goering et al. 2006; Hardiman 2007; Yates et al. 2011). However, these organizations are often involved in both service provision and advocacy activities (Goldstrom et al. 2006; Janzen et al. 2006; Tanenbaum 2012). Just like the 'social movement service organizations' conceptualized by Meyer (2010), many organizations are hybrid in activity. In these organizations, service provision and advocacy are intimately linked core activities where advocacy is seen as related to personal gain and service provisioning as empowering and political (Brown et al. 2007b; Stylianos and Kehyayan 2012; Tanenbaum 2011).

Gee et al. (2015) as well as Janzen et al. (2006) describe how MHSUO representatives are frequently invited to participate in policy development and community planning which currently constitute the core activities of many organizations. Practices like peer support and experiential knowledge have gained status and to some extent been incorporated into the traditional service system (Gillard et al. 2016). These developments in MHSUO activities have contributed to restructurings of the mental health field. By claiming discursive and material spaces, MHSUOs are now present in arenas where they used to be denied access. Practices developed in popular spaces are being transferred to traditional services and policy-making processes.

Conflicting perspectives on how to understand the current focus on service provision are evident in the material. Some argue that this could be seen as a radical development, where MHSUOs have claimed participatory spaces 
by creating alternatives to traditional mental health services based on service users' needs and knowledge. Others describe the associated dangers of professionalization, cooptation and less focus on political advocacy (Andersen and Svensson 2013; Ostrow and Adams 2012; Seebohm et al. 2010). These developments can furthermore cause role conflicts as MHSUOs straddle dual identities as partners with and opponents to traditional service systems (Crossley 2006).

\section{Processes of Organizational Professionalization}

MHSUOs aim to be different from traditional mental health services, often understood to be bureaucratic and oppressive (Nelson et al. 2006a). Alternative organizational forms have been developed in MHSUOs, involving high levels of volunteers, processes for democratic decision making and service user-exclusive groups (Boyce et al. 2010; Kleintjes et al. 2013b; Tanenbaum 2012). These aspects are described as unique features of MHSUOs and can be analyzed as constituting a counter-discourse that challenges the values and assumptions of hegemonic organizational models (Boyce et al. 2010; Brown et al. 2008a; Brown and Townley 2015; Kleintjes et al. 2013b; Nelson et al. 2006a). Grassroots activity in popular spaces, independent of traditional mental health service systems, is an important part of MHSUOs and vital for the development of alternative organizational models (Baumann 2014; Brown et al. 2007a).

However, the organizational forms of MHSUOs have been affected by their greater presence in invited and claimed spaces. Influenced as they are by traditional organizational forms, MHSUOs are increasingly dependent on receiving government funding, employing staff and becoming more like structured nonprofits (Brown et al. 2007a; Hodges and Hardiman 2006; Ostrow and Hayes 2015; Salem et al. 2008, 2010). Many organizations grapple with issues related to organizational structure in the current situation. MHSUOs are often part professional, part grassroots associations, operating in an organizational gray zone (Brown et al. 2007a). They may thus experience pressures from funders to professionalize and formalize, as well as opposing internal pressures to remain true to the core values of the service user movement (Boyce et al. 2010; Gillard et al. 2016; Meyer 2010).

Hodges and Hardiman (2006) describe how intersectoral cooperation in invited and claimed spaces potentially provides MHSUOs with a stronger voice, but also how it means that these organizations risk becoming increasingly similar to their public/private counterparts. Karlsson and Markström (2012) discuss this trend as a Faustian pact whereby organizations gain influence and resources by receiving public grants and contracts in return for delivering services. However, these very opportunities risk changing the key values of organizations (Karlsson and Markström 2012; Ostrow and Adams 2012). While professional partnerships can contribute to greater organizational capacity, they can also result in decreased service user control and a more formal and hierarchical organization (Salem et al. 2008, 2010).

Several studies focus on the ability of MHSUOs to accept invitations and claim new territory without sacrificing their unique organizational characteristics (e.g., Brown et al. 2007a; Hodges and Hardiman 2006). Brown et al. (2007a) explore goal tracking as a method of providing accountability to funders while maintaining service user control. Salem et al. (2010) recommend that MHSUOs clarify their values and roles and develop buffers for unwanted structural change before entering professional partnerships (Salem et al. 2010). Further examination is required to explore the opportunities for MHSUOs to operate in invited and claimed spaces while retaining their key organizational features.

\section{The Integration of Service User Knowledge}

The construction of recovery narratives and the sharing and revalorization of experiential knowledge are key characteristics of MHSUOs. Several studies describe the potential of MHSUOs to become arenas for experiential knowledge through providing space for sharing alternative narratives of self and recovery (Adame and Knudson 2007; Adame and Leitner 2008; Beresford and Branfield 2006; Chassot and Mendes 2015; Hoy 2014; Noorani 2013; Sapouna 2012; Woods 2013). Participation in countercultural communities in popular spaces, free from the involvement of the dominant system, is important in creating dialogical space for such alternative understandings of experience (Adame and Knudson 2007; Adame and Leitner 2008).

Gillard et al. (2016) and Janzen et al. (2006) describe how concepts and perspectives, such as recovery, experiential knowledge and empowerment, are currently being adapted in traditional mental health service systems. The included texts reflect this increased integration of service user perspectives where, for instance, empowerment and recovery scales are frequently applied to measure the outcomes of services provided by MHSUOs (Brown et al. 2008a; Corrigan 2006; Kaplan et al. 2012; Rogers et al. 2007). Rabeharisoa et al. (2014) discuss how service user groups can achieve change through constructing new political and scientific understandings of their experience. Knowledge production has enabled the service user movement to claim discursive space and thereby contribute to renegotiation of the hegemonic discourse.

However, several texts raise questions of whether concepts and perspectives such as empowerment and recovery 
could become coopted when incorporated into the professional system (Adame and Leitner 2008; Ostrow and Adams 2012). Adame and Leitner (2008), for example, discuss how empowerment has changed so as to mean individual choice over treatment rather than the redistribution of power resources. Beresford (2009) also discusses risks for cooptation of service user perspectives in relation to MHSUOs engaging in research activities in partnership. $\mathrm{He}$ argues that service user-controlled research in popular spaces holds greater potential for challenging hegemonic discourses and developing new forms of knowledge (Beresford 2009). The introduction of education programmes to develop expert patients is also critically discussed in the included texts and is related to risks of creating an increasingly stratified service user movement and rearticulating the hierarchies of psychiatry (Hopton 2006; Lakeman et al. 2007).

\section{Intensified Relationships with Traditional Mental Health Service Systems}

MHSUOs have claimed a seat at the policy table as a result of policy failures, system restructurings and political struggles (Bernstein 2006; Campbell 2008; Tomes 2006). This has resulted in evolved relationships with professionals and policy makers. Texts focused on MHSUO participation in policy processes examine service user participation in terms of the forms (Campbell 2008; Janzen et al. 2007; Stewart et al. 2008; Tse et al. 2012), barriers (Kleintjes et al. 2013a) and contributions (Battams and Johnson 2009; Borkmann and Munn-Giddings 2008; Vaughan and Arsneault 2008).

The growth in relationships between MHSUOs and traditional mental health service systems has created more invited spaces. The risks associated with these spaces are frequently discussed within texts focused on the context of Northern Europe (Beresford and Branfield 2006; Campbell 2008; de Freitas and Martin 2015; Markström and Karlsson 2013; Rose et al. 2016; Van de Bovenkamp and Trappenburg 2011). Adame and Leitner (2008) and Rose et al. (2016) contend that such collaborations must have an awareness of the risk of coopting service user groups into the mainstream discourse. MHSUOs have to a great extent adopted a collaborative approach, but Campbell (2008) questions whether sitting at the same table and being tied to the same agenda is the best course of action given the differences in perspective and status. Invitations from authorities, made on the assumption that the organizations are equal partners, can in fact restrict the freedom of MHSUOs (Markström and Karlsson 2013). Furthermore, high demands for MHSUO involvement in policy processes potentially compete with resources for popular initiatives outside mental health service systems (de Freitas and Martin 2015; Van de Bovenkamp and Trappenburg 2011).

Service user participation has come to be formulated through a consumerist discourse, framed in market terms and focused on treatment choice within mental health service systems. This focus excludes from the agenda broader social issues that affect the lives of service users (Battams and Johnson 2009; Beresford 2009; Campbell 2008). Several texts discuss a shallow acceptance of service user participation in invited spaces and question whether participation in such spaces has led to any significant change (Beresford and Branfield 2006; Bernstein 2006; Campbell 2008; Stewart et al. 2008; Tomes 2006). Battams and Johnson (2009) analyze service user participation as being largely an end in itself rather than a means to exercising real service user influence. Campbell (2008) argues that the novelty of sitting at the table should have worn off by now, with a shift in focus to the changes actually made. Mechanisms that require accountability on behalf of authority could potentially be helpful in dealing with issues of tokenism in invited spaces (Battams and Johnson 2009).

\section{Concluding Discussion}

MHSUOs parallel presence in popular, invited and claimed participatory spaces is central to the discussion in current research on the role of and challenges facing MHSUOs in the post-deinstitutional era. MHSUOs move through popular spaces, where alternative organizational structures, practices and forms of knowledge can be developed. MHSUOs have also occupied claimed spaces, where the core practices of the service user movement are becoming increasingly integrated into the professional service system and alternative services are being provided. Furthermore, MHSUOs have been invited by authorities into new territories by participating, for instance, in provisioning and policy formulation. How to make the most of their presence in new arenas, resist cooptation into hegemonic models and remain arenas for developing alternative practices are central questions that MHSUOs face in the current situation.

\section{Balancing the Political Opportunities of Participatory Spaces}

Participatory spaces are shaped by different discourses, institutional logics and power relations and therefore hold different political potential (Cornwall 2004). Balancing the political opportunities as well as the risks of different participatory spaces constitutes central challenges facing MHSUOs in the post-deinstitutional era. Even though 
popular spaces can be analyzed as being more radical, invited and claimed spaces also hold the potential to be transformed by the marginalized (Hickey and Mohan 2004). By offering connections to authorities, participation in claimed and invited spaces gives MHSUOs political opportunities to exercise their voice in relation to traditional mental health service systems. However, the political opportunities of these spaces do risk being undermined by tokenism, professionalization and the cooptation of service user perspectives. In reaction to this, the current situation is characterized by a shift in focus from gaining access to spaces controlled by authorities to a critical examination of the political opportunities available. The previous struggle of MHSUOs to be consulted is currently shifting toward demanding accountability and transparency on the part of authorities (cf. Cornwall and Gaventa 2000).

Even though claimed and invited spaces hold political potential, it is important to retain popular spaces in which the traditional mental health service system has no involvement. Such spaces are valuable resources for the mobilization of alternative perspectives and oppositional identities (Haug 2013) and are a requisite for citizen engagement moving beyond legitimization of the current system (Habermas 1996). Popular spaces might be perceived as 'laboratories of self-interest,' where service user groups can unite around political positions and demands before communicating these in other participatory domains (Cornwall and Schattan Coelho 2007, p. 18). de Freitas and Martin (2015) discuss the need to create arenas where marginalized groups and authorities can meet without these spaces becoming entrenched in bureaucracy and hegemonic discourses. We likewise understand the invitation of authorities to participate in spaces controlled by MHSUOs to hold the potential of offering the organizations connections to the state while avoiding state control (de Freitas and Martin 2015).

\section{Participation Beyond Psychiatry-Specific Spaces}

MHSUOs are active in a range of participatory spaces that provide opportunities for social and political participation at both individual and systemic levels. Included texts focus especially on the increased presence of MHSUOs in claimed and invited spaces, where participation is defined in relation to traditional mental health service systems. Tanenbaum (2012) describes how MHSUOs have the potential to become civic organizations by providing space for members to build social citizenship and develop community ties. Participation beyond 'psychiatry-specific' spaces is central to develop this potential of MHSUOs (Parr 2008; Rosenberg 2009). Such spaces could, for instance, be explored by evolved relationships with other civil society organizations. However, state incentives, whereby organizations are encouraged to engage in service provision or act as representatives in relation to traditional mental health service systems, mean that this civic potential of MHSUOs is often not fully explored (Tanenbaum 2011).

Exploring participation beyond psychiatry could also lead to a reformulated agenda that challenges consumerist discourses on participation. Participation can be defined as an extension of democracy and citizenship, but it is also associated with state retrenchment whereby the market is constructed as a 'surrogate arena for citizenship' (Cornwall and Schattan Coelho 2007, p. 5). The latter definition of participation involves service users being defined as both providers and consumers of services, and this needs to be distinct from participation focused on the redistribution of power (Cornwall and Gaventa 2000; Cornwall and Schattan Coelho 2007). MHSUOs exploring participation in issues that are not psychiatry-specific, such as housing policy and social insurance, could potentially allow for a shift from consumerist discourses focused on individual choice within the service system. A broadened participatory horizon could bring about an agenda that targets social and economic inequalities affecting the lives of service users.

To further the understanding of the current situation for MHSUOs, future studies will need to examine the strategies used by these organizations to manage professional partnerships, as well as MHSUO community ties and participation in spaces and issues that are not psychiatryspecific. The fact that it is an increasingly important social and political arena means that we also need to develop an understanding of the political opportunities offered through online spaces for service user mobilization.

Acknowledgements This article constitutes a part of the research project 'Mental health service user movements post deinstitutionalization-forms of organization and attitudes to services,' funded by the Swedish Research Council for Health, Working Life and Welfare (Grant No. 2015-00414).

Funding This study was funded by the Swedish Research Council for Health, Working Life and Welfare (Grant No. 2015-00414).

\section{Compliance with ethical standards}

Conflict of interest The authors declare that they have no conflict of interest.

Open Access This article is distributed under the terms of the Creative Commons Attribution 4.0 International License (http://crea tivecommons.org/licenses/by/4.0/), which permits unrestricted use, distribution, and reproduction in any medium, provided you give appropriate credit to the original author(s) and the source, provide a link to the Creative Commons license, and indicate if changes were made. 


\section{References}

Abdulmalik, J., Fadahunsi, W., Kola, L., Nwefoh, E., Minas, H., Eaton, J., et al. (2014). The Mental Health Leadership and Advocacy Program (mhLAP): A pioneering response to the neglect of mental health in Anglophone West Africa. International Journal of Mental Health Systems, 8(1), 1-9.

Adame, A. L., \& Knudson, R. M. (2007). Beyond the counternarrative-exploring alternative narratives of recovery from the psychiatric survivor movement. Narrative Inquiry, 17(2), 157-178.

Adame, A. L., \& Leitner, L. M. (2008). Breaking out of the mainstream: The evolution of peer support alternatives to the mental health system. Ethical Human Psychology and Psychiatry, 10(3), 146-162.

Andersen, A. J. W., \& Svensson, T. (2013). Internet-based mental health services in Norway and Sweden: Characteristics and consequences. Administration and Policy in Mental Health and Mental Health Services Research, 40(2), 145-153.

Barrett, D., Benson, J., Foster, R., \& Leader, A. (2014). Prosper: A social movement approach to mental health. Mental Health and Social Inclusion, 18(4), 188-197.

Battams, S., \& Johnson, A. (2009). The influence of service users and NGOs on housing for people with psychiatric disability. Health Sociology Review, 18(3), 321-334.

Baumann, A. E. (2014). Non-governmental organizations as key partners in mental health in Europe. Die Psychiatrie: Grundlagen \& Perspektiven, 11(1), 27-34.

Baumeister, R. F., \& Leary, M. R. (1997). Writing narrative literature reviews. Review of General Psychology, 1(3), 311-320.

Beresford, P. (2009). User controlled research. In J. Wallcraft, B. Schrank, \& M. Amering (Eds.), Handbook of service user involvement in mental health research. Wiley-Blackwell: Singapore.

Beresford, P., \& Branfield, F. (2006). Developing inclusive partnerships: User-defined outcomes, networking and knowledge-a case study. Health and Social Care in the Community, 14(5), 436-444.

Bernstein, R. (2006). A seat at the table: Trend or illusion? Health Aff (Millwood), 25(3), 730-733.

Best, P., Manktelow, R., \& Taylor, B. (2014). Online communication, social media and adolescent wellbeing: A systematic narrative review. Children and Youth Services Review, 41, 27-36.

Borkmann, T., \& Munn-Giddings, C. (2008). Self-help groups challenge health care systems in the US. In S. M. Chambré \& S. Goldner (Eds.), Patients, consumers and civil society (Advances in medical sociology, Volume 10) (pp. 127-150). Bingley: Emerald Group Publishing Limited.

Boyce, M., Munn-Giddings, C., Smith, L., \& Campbell, S. (2010). Innovatory features and challenges facing mental health user-led organizations. Mental Health Review Journal, 15(2), 34-42.

Brown, L. D. (2009a). How people can benefit from mental health consumer-run organizations. American Journal of Community Psychology, 43(3-4), 177-188.

Brown, L. D. (2009b). Making it sane: Using narrative to explore theory in a mental health consumer-run organization. Qualitative Health Research, 19(2), 243-257.

Brown, L. D., Shepherd, M. D., Merkle, E. C., Wituk, S. A., \& Meissen, G. (2008a). Understanding how participation in a consumer-run organization relates to recovery. American Journal of Community Psychology, 42(1-2), 167-178.

Brown, L. D., Shepherd, M. D., Wituk, S. A., \& Meissen, G. (2007a). Goal achievement and the accountability of consumer-run organizations. Journal of Behavioral Health Services and Research, 34(1), 73-82.
Brown, L. D., Shepherd, M. D., Wituk, S. A., \& Meissen, G. (2007b). How settings change people: Applying behavior setting theory to consumer-run organizations. Journal of Community Psychology, 35(3), 399-416.

Brown, L. D., Shepherd, M. D., Wituk, S. A., \& Meissen, G. (2008b). Introduction to the special issue on mental health self-help. American Journal of Community Psychology, 42(1-2), 105-109.

Brown, L. D., \& Townley, G. (2015). Determinants of engagement in mental health consumer-run organizations. Psychiatric Services, 66(4), 411-417.

Brown, L. D., Wituk, S., \& Meissen, G. (2010). Consumer-run dropin centers: Current state and future directions mental health selfhelp: Consumer and family initiatives (pp. 155-167). New York, NY: Springer.

Burns, T. (2014). Community psychiatry's achievements. Epidemiology and Psychiatric Sciences, 23(4), 337-344.

Campbell, P. (2008). Service user involvement. In T. Stickley \& T. Basset (Eds.), Learning about mental health practice (pp. 291-309). Chichester: Wiley.

Chassot, C. S., \& Mendes, F. (2015). The experience of mental distress and recovery among people involved with the service user/survivor movement. Health, 19(4), 372-388.

Cornwall, A. (2002). Making spaces, changing places: Situating participation in devlopment. IDS working paper, 170. Brighton: IDS.

Cornwall, A. (2004). Spaces for transformation? Reflections on issues of power and difference in participation in development. In S. Hickey \& G. Mohan (Eds.), Participation: From tyranny to transformation? Exploring new approaches to participation in development (pp. 75-93). London: Zed Books Ltd.

Cornwall, A. (2008). Unpacking 'participation': Models, meanings and practices. Community Development Journal, 43(3), 269-283.

Cornwall, A., \& Gaventa, J. (2000). From users and choosers to makers and shapers-repositioning participation in social policy. Ids Bulletin-Institute of Development Studies, 31(4), 50-62.

Cornwall, A., \& Schattan Coelho, V. (2007). Spaces for change? The politics of citizen participation in new democratic arenas. In A. Cornwall \& V. Schattan Coelho (Eds.), Spaces for change? The politics of citizen participation in new democratic arenas (pp. 1-32). London: Zed Books Ltd.

Cornwall, A., \& Shankland, A. (2013). Cultures of politics, spaces of power: contextualizing Brazilian experiences of participation. Journal of Political Power, 6(2), 309-333.

Corrigan, P. W. (2006). Impact of consumer-operated services on empowerment and recovery of people with psychiatric disabilities. Psychiatric Services, 57(10), 1493-1496.

Crossley, N. (2006). Contesting psychiatry: Social movements in mental health. Oxford: Routledge.

de Freitas, C., \& Martin, G. (2015). Inclusive public participation in health: Policy, practice and theoretical contributions to promote the involvement of marginalised groups in healthcare. Social Science and Medicine, 135, 31-39.

Dziadkowiec, O., Reinhart, C., Vu, C. C., Shagott, T., Keele-Lien, A., Banta, A., et al. (2010). A statewide collaboration to build the leadership and organizational capacity of Consumer-Run Organizations (CROs). In L. D. Brown \& S. Wituk (Eds.), Mental health self-help: Consumer and family initiatives (pp. 287-300). New York, NY: Springer.

Eriksson, E. (2015). Sanktionerat motstånd: Brukarinflytande som fenomen och praktik. Lund: Lunds universitet.

Fleury, M.-J., Grenier, G., Bamvita, J.-M., Wallot, H., \& Perreault, M. (2012). Determinants of referral to the public health care and social sector by nonprofit organizations: Clinical profile and interorganizational characteristics. Nonprofit \& Voluntary Sector Quarterly, 41(2), 257-279. 
Gaventa, J. (2004). Towards participatory governance: Assessing the transformative possibilities. In S. Hickey \& G. Mohan (Eds.), Participation: From tyranny to transformation? Exploring new approaches to participation in development (pp. 25-41). London: Zed Books Ltd.

Gaventa, J., \& Valderrama, C. (1999). Participation, citizenship and local governance. Background note prepared for workshop 'strengthening participation in local governance'. Brighton: IDS.

Gee, A., McGarty, C., \& Banfield, M. (2015). What drives systemic mental health advocates? Goals, strategies, and values of Australian consumer and carer advocacy organizations. SAGE Open, 1-8.

Gillard, S., Foster, R., \& Turner, K. (2016). Evaluating the prosper peer-led peer support network: A participatory, coproduced evaluation. Mental Health and Social Inclusion, 20(2), 80-91.

Goering, P., Durbin, J., Sheldon, C. T., Ochocka, J., Nelson, G., \& Krupa, T. (2006). Who uses consumer-run self-help organizations? American Journal of Orthopsychiatry, 76(3), 367-373.

Goldstrom, I. D., Campbell, J., Rogers, J. A., Lambert, D. B., Blacklow, B., Henderson, M. J., et al. (2006). National estimates for mental health mutual support groups, self-help organizations, and consumer-operated services. Administration and Policy in Mental Health, 33(1), 92-103.

Gupta, E., \& Roberts, B. (2014). User and researcher collaborations in mental health in low and middle income countries: A case study of the EMPOWER project. BMC Research Notes, 7(1), 1-6.

Habermas, J. (1996). Between facts and norms: Contributions to a discourse theory of law and democracy. Cambridge, MA: MIT Press.

Hardiman, E. R. (2007). Referral to consumer-run programs by mental health providers: A national survey. Community Mental Health Journal, 43(3), 197-210.

Haug, C. (2013). Organizing spaces: Meeting arenas as a social movement infrastructure between organization, network, and institution. Organization Studies, O(0), 1-28.

Hickey, S., \& Mohan, G. (2004). Towards participation as transformation: Critical themes and challenges. In S. Hickey \& G. Mohan (Eds.), Participation: From tyranny to transformation? Exploring new approaches to participation in development (pp. 3-24). London: Zed Books Ltd.

Hodges, J. Q., \& Hardiman, E. R. (2006). Promoting healthy organizational partnerships and collaboration between consumer-run and community mental health agencies. Administration and Policy in Mental Health and Mental Health Services Research, 33(3), 267-278.

Holland, D. (2010). Social entrepreneurs and NGOs for people with mental disabilities in post-communist Europe: Implications for international policy. Review of Disability Studies: An International Journal, 6(4), 7-24.

Hopton, J. (2006). The future of critical psychiatry. Critical Social Policy, 26(1), 57-73.

Hoy, J. M. (2014). Consumer-operated service program members' explanatory models of mental illness and recovery. Qualitative Health Research, 24(10), 1400-1406.

Janzen, R., Nelson, G., Hausfather, N., \& Ochocka, J. (2007). Capturing system level activities and impacts of mental health consumer-run organizations. American Journal of Community Psychology, 39(3-4), 287-299.

Janzen, R., Nelson, G., Trainor, J., \& Ochocka, J. (2006). A longitudinal study of mental health consumer/survivor initiatives: Part 4-benefits beyond the self? A quantitative and qualitative study of system-level activities and impacts. Journal of Community Psychology, 34(3), 285-303.

Kaplan, K., Salzer, M. S., \& Brusilovskiy, E. (2012). Community participation as a predictor of recovery-oriented outcomes among emerging and mature adults with mental illnesses. Psychiatric Rehabilitation Journal, 35(3), 219-229.

Karlsson, M., \& Markström, U. (2012). Non-profit organizations in mental health: Their roles as seen in research. VOLUNTAS: International Journal of Voluntary and Nonprofit Organizations, 23(2), 287-301.

Kleintjes, S., Lund, C., \& Swartz, L. (2013a). Barriers to the participation of people with psychosocial disability in mental health policy development in South Africa: A qualitative study of perspectives of policy makers, professionals, religious leaders and academics. BMC International Health and Human Rights, 13(1), 1-10.

Kleintjes, S., Lund, C., \& Swartz, L. (2013b). Organising for selfadvocacy in mental health: Experiences from seven African countries. African Journal of Psychiatry (South Africa), 16(3), $187-195$.

Lakeman, R., Cook, J., McGowan, P., \& Walsh, J. (2007). Service users, authority, power and protest: A call for renewed activism. Mental Health Practice, 11(4), 12-16.

Markström, U. (2005). Avinstitutionalisering och post-avinstitutionalisering. In D. Brunt \& L. Hansson (Eds.), Att leva med psykisk funktionsnedsättning_livssitutaion och effektiva vård och stödinsatser (2nd ed.). Lund: Studentlitteratur.

Markström, U., \& Karlsson, M. (2013). Towards hybridization: The roles of Swedish non-profit organizations within mental health. VOLUNTAS: International Journal of Voluntary and Nonprofit Organizations, 24(4), 917-934.

Markström, U., \& Lindqvist, R. (2015). Establishment of community mental health systems in a postdeinstitutional era: A study of organizational structures and service provision in Sweden. Journal of Social Work in Disability \& Rehabilitation, 14(2), $124-144$.

Meyer, M. (2010). Social movement service organizations: The challenges and consequences of combining service provision and political advocacy. In Y. Hasenfeld (Ed.), Human services as complex organizations (2nd ed., pp. 533-550). London: Sage Publications.

Nelson, G., Janzen, R., Trainor, J., \& Ochocka, J. (2008). Putting values into practice: Public policy and the future of mental health consumer-run organizations. American Journal of Community Psychology, 42(1-2), 192-201.

Nelson, G., \& Lomotey, J. (2006). Quantity and quality of participation and outcomes of participation in mental health consumerrun organizations. Journal of Mental Health, 15(1), 63-74.

Nelson, G., Ochocka, J., Janzen, R., \& Trainor, J. (2006a). A longitudinal study of mental health consumer/survivor initiatives: Part 1-literature review and overview of the study. Journal of Community Psychology, 34(3), 247-260.

Nelson, G., Ochocka, J., Janzen, R., \& Trainor, J. (2006b). A longitudinal study of mental health consumer/survivor initiatives: Part 2-a quantitative study of impacts of participation on new members. Journal of Community Psychology, 34(3), 261-272.

Nelson, G., Ochocka, J., Janzen, R., Trainor, J., Goering, P., \& Lomotey, J. (2007). A longitudinal study of mental health consumer/survivor initiatives: Part V-outcomes at 3-year follow-up. Journal of Community Psychology, 35(5), 655-665.

Noorani, T. (2013). Service user involvement, authority and the 'expert-by-experience' in mental health. Journal of Political Power, 6(1), 49-68.

Ostrow, L., \& Adams, N. (2012). Recovery in the USA: From politics to peer support. International Review of Psychiatry, 24(1), $70-78$.

Ostrow, L., \& Hayes, S. L. (2015). Leadership and characteristics of nonprofit mental health peer-run organizations nationwide. Psychiatric Services, 66(4), 421-425. 
Parr, H. (2008). Mental health and social space: Towards inclusionary geographies?. Oxford: Blackwell Publishing.

Patterson, S., Trite, J., \& Weaver, T. (2014). Activity and views of service users involved in mental health research: UK survey. British Journal of Psychiatry, 205(1), 68-75.

Rabeharisoa, V., Moreira, T., \& Akrich, M. (2014). Evidence-based activism: Patients', users' and activists' groups in knowledge society introduction. Biosocieties, 9(2), 111-128.

Rogers, E. S. (2010). Consumer and consumer-supporter national technical assistance centers: Helping the consumer movement grow and transform systems. In L. D. Brown \& S. Wituk (Eds.), Mental health self-help: Consumer and family initiatives (pp. 265-286). New York, NY: Springer.

Rogers, E. S., Teague, G. B., Lichenstein, C., Campbell, J., Lyass, A., Chen, R., et al. (2007). Effects of participation in consumeroperated service programs on both personal and organizationally mediated empowerment: Results of multisite study. Journal of Rehabilitation Research and Development, 44(6), 785-799.

Rose, D. (2015). The contemporary state of service-user-led research. Lancet Psychiatry, 2(11), 959-960.

Rose, D., Fleischmann, P., Tonkiss, F., Campbell, P., \& Wykes, T. (2003). Review of the literature: User and career involvement in change management in mental health context. Report to the National Co-ordinating Centre for NHS Service Delivery and Organisation R \& D (NCCSDO). London: Institute of Psychiatry.

Rose, D., MacDonald, D., Wilson, A., Crawford, M., Barnes, M., \& Omeni, E. (2016). Service user led organisations in mental health today. Journal of Mental Health, 25(3), 254-259.

Rosenberg, D. (2009). Psychiatric disability in the community. Surveying the social landscape in the post-deinstitutional era. Umeå: Umeå University.

Salem, D. A., Reischl, T. M., \& Randall, K. W. (2008). The effect of professional partnership on the development of a mutual-help organization. American Journal of Community Psychology, 42(1-2), 179-191.

Salem, D. A., Reischl, T. M., \& Randall, K. (2010). Helping mutual help: Managing the risks of professional partnerships. In L. D. Brown \& S. Wituk (Eds.), Mental health self-help: Consumer and family initiatives (pp. 303-334). New York, NY: Springer.

Sapouna, L. (2012). Foucault, Michel. Madness and civilization: A history of insanity (2001). Community Development Journal, 47(4), 612-617.
Seebohm, P., Munn-Giddings, C., \& Brewer, P. (2010). What's in a name? A discussion paper on the labels and location of selforganising community groups, with particular reference to mental health and Black groups. Mental Health and Social Inclusion, 14(3), 23-29.

Stewart, S., Watson, S., Montague, R., \& Stevenson, C. (2008). Set up to fail? Consumer participation in the mental health service system. Australasian Psychiatry, 16(5), 348-353.

Stylianos, S., \& Kehyayan, V. (2012). Advocacy: Critical component in a comprehensive mental health system. American Journal of Orthopsychiatry, 82(1), 115-120.

Swarbrick, M. (2007). Consumer-operated self-help centers. Psychiatric Rehabilitation Journal, 31(1), 76-79.

Tanenbaum, S. J. (2011). Mental health consumer-operated services organizations in the US: Citizenship as a core function and strategy for growth. Health Care Analysis, 19(2), 192-205.

Tanenbaum, S. J. (2012). Consumer-operated service organizations: Organizational characteristics, community relationships, and the potential for citizenship. Community Mental Health Journal, 48(4), 397-406.

Tomes, N. (2006). The patient as a policy factor: A historical case study of the consumer/survivor movement in mental health. Health Affairs, 25(3), 720-729.

Truc Huynh, T. (2014). Service users' participation in mental health community-based organizations. Ann Arbor: Université de Montréal.

Tse, S., Cheung, E., Kan, A., Ng, R., \& Yau, S. (2012). Recovery in Hong Kong: Service user participation in mental health services. International Review of Psychiatry, 24(1), 40-47.

Van de Bovenkamp, H. M., \& Trappenburg, M. J. (2011). Government influence on patient organizations. Health Care Analysis, 19(4), 329-351.

Vaughan, S. K., \& Arsneault, S. (2008). Not-for-profit advocacy: Challenging policy images and pursuing policy change. Review of Policy Research, 25(5), 411-428.

Werkmeister Rozas, L., \& Klein, W. C. (2010). The value and purpose of the traditional qualitative literature review. Journal of Evidence-Based Social Work, 7(5), 387-399.

Woods, A. (2013). The voice-hearer. Journal of Mental Health, 22(3), 263-270.

Yates, B. T., Mannix, D., Freed, M. C., Campbell, J., Johnsen, M., Jones, K., et al. (2011). Consumer-operated service programs: Monetary and donated costs and cost-effectiveness. Psychiatric Rehabilitation Journal, 35(2), 91-99. 